\title{
Removal of 4-chloro-2-nitrophenol occurring in drug and pesticide waste by adsorption onto nano-titanium dioxide
}

\author{
A. Mehrizad $\cdot$ K. Zare $\cdot$ H. Aghaie $\cdot$ \\ S. Dastmalchi
}

Received: 4 June 2011/Revised: 30 October 2011/Accepted: 21 December 2011/Published online: 10 March 2012

(c) CEERS, IAU 2012

\begin{abstract}
The present study deals with removal of 4-chloro-2-nitrophenol (4C2NP) as a model contaminant from pharmaceutical and pesticide industries using titanium dioxide nanoparticles as an adsorbent. 4C2NP is recalcitrant and persistent toward biodegradation and its generation in aqueous environment during formulation, distribution and field application of pesticides is often unavoidable. Batch experiments were carried out to investigate the effect of contact time, nano-titanium dioxide dosage, initial $\mathrm{pH}$, initial $4 \mathrm{C} 2 \mathrm{NP}$ concentration and temperature on adsorption efficiency. The results showed that the adsorption capacity was increased with increasing $4 \mathrm{C} 2 \mathrm{NP}$ concentration and temperature. Optimum conditions for $4 \mathrm{C} 2 \mathrm{NP}$ adsorption were found to be initial $\mathrm{pH} \approx 2$, nano-titanium dioxide dosage $\approx 0.01 \mathrm{~g} / 250 \mathrm{~mL}$ and equilibrium time $\approx 1 \mathrm{~h}$. Titanium dioxide nanoparticles recorded a maximum capacity of $86.3 \mathrm{mg} / \mathrm{g}$ at optimal conditions. The linear correlation coefficients of Langmuir, Freundlich and Temkin isotherms were obtained. The results revealed that the Freundlich isotherm fitted the experimental data better than the other isotherm models.
\end{abstract}

Keywords Nanoparticle - Phenolic compounds . Adsorption isotherm - Wastewater

\footnotetext{
A. Mehrizad $(\bowtie) \cdot$ K. Zare $\cdot$ H. Aghaie

Department of Chemistry, Science and Research Branch, Islamic Azad University, Tehran, Iran

e-mail: ali.mehrizad@yahoo.com

S. Dastmalchi

Biotechnology Research Center and School of Pharmacy,

Tabriz University of Medical Sciences, Tabriz, Iran
}

\section{Introduction}

Environmental pollution due to technological developments is one of the most important problems of this century. Industrial use of phenol and its derivatives over the past decades has led to serve environmental pollution. These compounds are toxic and carcinogenic, and they can persist for many years in the environment because of their resistance to microbiological degradation (Khan and Anjaneyulu 2005; Chen et al. 2009). Owing to their toxicity, their polluting effects on our echo-system provide possible human health risk. Chronic toxic effects due to phenols reported in humans include vomiting, difficulty in swallowing, anorexia, liver and kidney damages, headache, fainting and other mental disturbances (Calace et al. 2002). While the World Health Organization (WHO) has recommended the permissible phenolic concentration of $0.001 \mathrm{mg} / \mathrm{L}$ in potable waters, the European Union (EU) has set a maximum concentration level of $0.5 \mu \mathrm{g} / \mathrm{dm}^{3}$ of total phenols in drinking water (WHO 1963; Dursun and Tepe 2005). Moreover, the maximum permitted concentration level of phenols being $0.5-1 \mathrm{mg} / \mathrm{L}$ for industrial wastewaters (Sokol and Korpal 2004). Thus, the removal of phenolic compounds from wastewater before its discharge, is necessary to reduce their side effects on the environment and human health. In the last decade, various methods have been proposed to remove phenols, including advanced oxidation process (Samarghandi et al. 2007; Saritha et al. 2007), biological degradation (Agarry and Solomon, 2008), ultrafiltration (Acero et al. 2005), ozonation (Benitez et al. 2000; Gharbani et al. 2010) and adsorption (Hashizume 2004; Roostaei and Tezel 2004; Mahvi 2008; Dabhade et al. 2009; Subramanyam and Das 2009; Belarbi and Al-Malack 2010). Since the other methods need special process requirements or special catalysts, adsorption seems 
to be a good choice in terms of cost and operation for removal of phenol and its derivatives.

Activated carbon (Gonzalez-Serrano et al. 2004; Kumar et al. 2007; Tseng et al. 2010), microporous and mesoporous carbon (Derylo-Marczewska et al. 2010; Haque et al. 2010), Zeolit (Wang et al. 2010) and clay minerals (Arellano-Cardenas et al. 2005) are a few of the adsorptive materials which have been tested for adsorption of phenols from aqueous solutions. In most cases, adsorbents have diameters in the range of submicron to micron and have large internal porosities to ensure adequate surface area for adsorption. However, the diffusion limitation within the particles leads to decreases in the adsorption rate and available capacity. Therefore, it is important and interesting to develop a novel adsorbent with a large surface area, small diffusion resistance and high capacity for adsorption. The relative large specific surface area of nanoparticles enables them to become candidate for adsorption of phenol and substituted phenols. Nanoparticles have high-adsorption capacity. In addition, the operation is simple and the adsorption process is rapid (Lei et al. 2010). Some researches have reported that nanosized inorganic oxides such as nano- $\mathrm{TiO}_{2}$ could successfully remove phenolic compounds from contaminated water (Robert et al. 2000; Bekkouche et al. 2004).

In this research, efficiency and performance of nano- $\mathrm{TiO}_{2}$ in adsorption of USEPA listed 4-chloro-2-nitrophenol (4C2NP), widely available in bulk drug and pesticide wastes, was studied. The study was carried out aiming at optimization of conditions for removal of 4C2NP from aqueous solutions by nano- $\mathrm{TiO}_{2}$ adsorbent. Moreover, experimental data fitted various isotherm equations to determine the best isotherm to correlate the experimental data. The experiments were conducted in School of Pharmacy, Tabriz University of Medical Sciences, during 2010-2011.

\section{Materials and methods}

Nano- $\mathrm{TiO}_{2}$ (Degussa P25) was purchased from Degussa, Germany. Particle size and surface area of nanoparticles were about $20 \mathrm{~nm}$ and $15-50 \mathrm{~m}^{2} / \mathrm{g}$, respectively. 4C2NP $\left(\mathrm{C}_{6} \mathrm{H}_{4} \mathrm{ClNO}_{3}, M_{\mathrm{w}}=173.56 \mathrm{~g} / \mathrm{mol}\right)$ was supplied by Fluka, Germany.

Adsorption of 4C2NP was carried out by a batch method to obtain equilibrium data. The variation of the $4 \mathrm{C} 2 \mathrm{NP}$ concentration versus time in the aqueous solution was monitored under various conditions such as nano- $\mathrm{TiO}_{2}$ dosage $(0.005,0.01,0.02,0.03,0.04,0.05$ and 0.1 $\mathrm{g} / 250 \mathrm{~mL})$, initial $\mathrm{pH}(2,4,6,8,10$ and 12$)$, initial 4C2NP concentration $(2,4,6,8$ and $10 \mathrm{mg} / \mathrm{L})$ and temperature $(25$, 35,45 and $55^{\circ} \mathrm{C}$ ). A stock solution was prepared by dissolving the required amount of $4 \mathrm{C} 2 \mathrm{NP}$ in ethanol (from
Merck) and then diluting it to the appropriate concentration by double-distilled water ( $\mathrm{pH}$ of stock solution was 5.7). The initial $\mathrm{pH}$ was adjusted by adding either $\mathrm{HCl}$ or $\mathrm{NaOH}$. Adsorption was achieved by adding a known amount of nano$\mathrm{TiO}_{2}$ into $250 \mathrm{~mL}$ of $4 \mathrm{C} 2 \mathrm{NP}$ solution of known concentration, $\mathrm{pH}$ and temperature, and the mixture was shaken in a shaking water bath at a speed of 140 shakes/min. Samples were taken at predetermined time intervals, centrifuged (Hettich/UNIVERSAL 16-R) at 10,000 rpm for $10 \mathrm{~min}$ and the analysis of $4 \mathrm{C} 2 \mathrm{NP}$ remaining in the solution was done using a UV-160 Shimadzu spectrophotometer at a wavelength of $219 \mathrm{~nm}$ (acidic pHs) or $234 \mathrm{~nm}$ (neutral and alkaline pHs). 4C2NP concentration was calculated from the calibration curve. The calibration graph was constructed using several points as absorbance versus $4 \mathrm{C} 2 \mathrm{NP}$ concentration in the range of $2-10 \mathrm{mg} / \mathrm{L}$ and the results evaluated by liner regression. The adsorbed 4C2NP amounts onto the $\mathrm{TiO}_{2}$ nanoparticles $(\mathrm{mg} / \mathrm{g})$ were calculated from the following relation:

$q_{t}=\frac{\left(C_{0}-C_{t}\right)}{M} V$

$q_{\mathrm{e}}=\frac{\left(C_{0}-C_{\mathrm{e}}\right)}{M} V$

where $C_{0}, C_{t}$ and $C_{\mathrm{e}}$ are the initials, at any time $t$ and equilibrium 4C2NP concentration $(\mathrm{mg} / \mathrm{L})$, respectively; $V$ is solution volume (L); and $M$ is nano- $\mathrm{TiO}_{2}$ mass (g).

\section{Results and discussion}

\section{Effect of contact time}

To find out the optimum contact time, $0.1 \mathrm{~g}$ of nano- $\mathrm{TiO}_{2}$ was added to $250 \mathrm{~mL}$ of $4 \mathrm{C} 2 \mathrm{NP}$ solution with concentration of $10 \mathrm{mg} / \mathrm{L}$ at $25^{\circ} \mathrm{C}$. The $\mathrm{pH}$ of solution was 5.7 and was not corrected. The mixture was shaken for $180 \mathrm{~min}$ and samples were taken at $10 \mathrm{~min}$ intervals (Fig. 1).

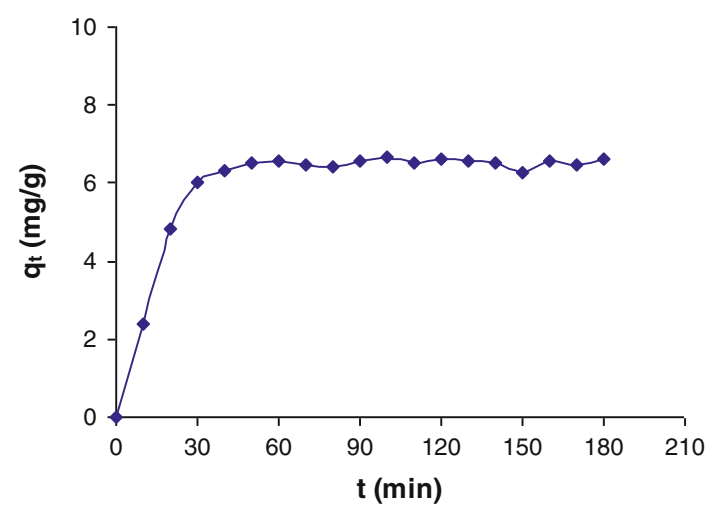

Fig. 1 Effect of contact time on 4C2NP adsorption onto nano- $\mathrm{TiO}_{2}$ (nano- $\mathrm{TiO}_{2}$ dose: $0.1 \mathrm{~g} / 250 \mathrm{~mL}$, $\mathrm{pH}$ : 5.7, initial 4C2NP conc.: $10 \mathrm{mg} / \mathrm{L}$, temp.: $25^{\circ} \mathrm{C}$ ) 
The removal of $4 \mathrm{C} 2 \mathrm{NP}$ by adsorption onto nano- $\mathrm{TiO}_{2}$ was found to be rapid at the initial period of contact time, and then slowed with the increase of contact time. This is obvious from the fact that a large number of vacant surface sites are available for adsorption during the initial stage and with passage of time, the remaining vacant surface sites are difficult to be occupied due to repulsive forces between the solute molecules on the solid phase and in the bulk liquid phase. Figure 1 also indicates that the time required for equilibrium is $1 \mathrm{~h}$. Thus, for all equilibrium adsorption studies, the contact period was kept $1 \mathrm{~h}$.

Effect of nano- $\mathrm{TiO}_{2}$ dosage

To study the effect of nano- $\mathrm{TiO}_{2}$ dose on the adsorption of $4 \mathrm{C} 2 \mathrm{NP}$, the experiments were done under the conditions described at the previous stage with contact time of $1 \mathrm{~h}$ and variable nano- $\mathrm{TiO}_{2}$ dose $(0.005,0.01,0.02,0.03$, $0.04,0.05$ and $0.1 \mathrm{~g} / 250 \mathrm{~mL}$ ). Figure 2 shows the effect of nano- $\mathrm{TiO}_{2}$ dosage on removal of $4 \mathrm{C} 2 \mathrm{NP}$. A trend of increment in adsorption capacity with increment in adsorbent dose was observed from 0.005 to $0.01 \mathrm{~g} / 250 \mathrm{~mL}$. Adsorbent recorded a maximum capacity of $77.78 \mathrm{mg} / \mathrm{g}$ at $0.01 \mathrm{~g} / 250 \mathrm{~mL}$ dosage. The initial increment in adsorption capacity with an increase in adsorbent dosage was expected, since number of adsorbent particles increases, and thus, more surface areas were available. Further increment in adsorbent dosage beyond maximum adsorption capacity at $0.01 \mathrm{~g} / 250 \mathrm{~mL}$ led to the decline in capacity, as shown in Fig. 2. This reduction in capacity had been explained as due to the aggregation of nano- $\mathrm{TiO}_{2}$ particles, which reduced the interfacial area between the reaction solution and the adsorbent. However, similar observations can be found in literature. Saritha et al. (2007), who utilized $\mathrm{TiO}_{2}$ powder to adsorb 4C2NP, suggested that the amount adsorbed $(\mathrm{mg} / \mathrm{g})$ decreased as the amount of the adsorbent increased. As a result, nano- $\mathrm{TiO}_{2}$ dosage of $0.01 \mathrm{~g} / 250 \mathrm{~mL}$ was used in the subsequent experiments of this work.

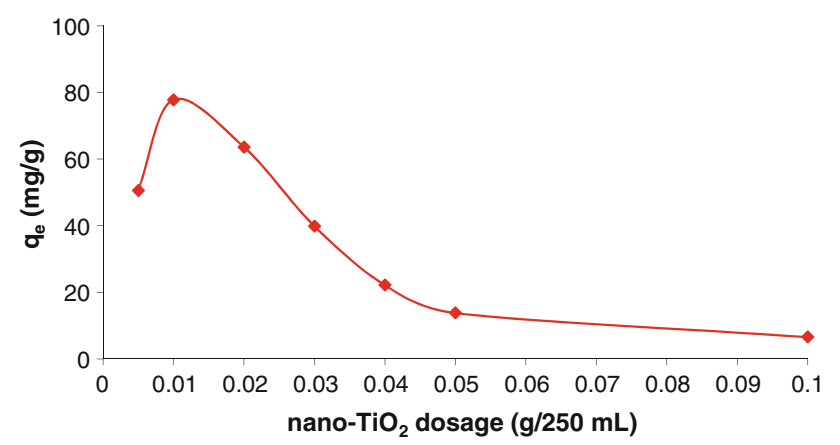

Fig. 2 Effect of nano- $\mathrm{TiO}_{2}$ dosage on $4 \mathrm{C} 2 \mathrm{NP}$ adsorption (pH: 5.7, initial $4 \mathrm{C} 2 \mathrm{NP}$ conc.: $10 \mathrm{mg} / \mathrm{L}$, temp.: $25^{\circ} \mathrm{C}$, contact time: $1 \mathrm{~h}$ )
Effect of initial $\mathrm{pH}$

In this study, understanding of $\mathrm{pH}$ was important, because, the $\mathrm{pH}$ of the solution influences the distribution of active sites on the surface of nano- $\mathrm{TiO}_{2}$. To determination the effects of solution $\mathrm{pH}$ on adsorption capacity; 4C2NP adsorption was examined by adding different amounts of $0.1 \mathrm{M} \mathrm{HCl}$ or $0.1 \mathrm{M} \mathrm{NaOH}$ to obtain different pHs (i.e., 2, 4, 6, 8, 10 and 12). In Fig. 3, the effect of initial $\mathrm{pH}$ on the adsorption of $4 \mathrm{C} 2 \mathrm{NP}$ onto nano- $\mathrm{TiO}_{2}$ at $25^{\circ} \mathrm{C}$ and initial $4 \mathrm{C} 2 \mathrm{NP}$ concentration of $10 \mathrm{mg} / \mathrm{L}$ is depicted. As shown, it can be deduced that the amount of $4 \mathrm{C} 2 \mathrm{NP}$ adsorbed on nano- $\mathrm{TiO}_{2}$ increased by decreasing $\mathrm{pH}$ and the highest amount of $4 \mathrm{C} 2 \mathrm{NP}$ adsorption was at $\mathrm{pH} 2(86.3 \mathrm{mg} / \mathrm{g})$.

The $\mathrm{pH}$ solution controls the electrostatic interactions between the adsorbent and the adsorbate (Anbia and Ghaffari 2009). The adsorbent surface charge is neutral at isoelectric point (IEP), where the $\mathrm{pH}_{\mathrm{IEP}}$ for the Degussa $\mathrm{P} 25 \mathrm{TiO}_{2}$ is ranged between 6.2 and 6.9 (Bourikas et al. 2005). While the surface of the adsorbent carries positive charge at $\mathrm{pH}$ values lower than IEP, it has negative charge at $\mathrm{pH}$ values higher than IEP (Lei et al. 2010). At low $\mathrm{pH}$ of 6 , nano- $\mathrm{TiO}_{2}$ surface is positively charged and since there is no electrostatic repulsion between the unionized 4C2NP species and the positively charged surface, the adsorption is higher. On the other hand, for $\mathrm{pH}>\mathrm{pK}_{\mathrm{a}}$ (4C2NP, $\mathrm{pK}_{\mathrm{a}}=6.46$ ), the phenols dissociate, forming phenolate anions, while the surface of nano- $\mathrm{TiO}_{2}$ is negatively charged. The electrostatic repulsion between the identical charges lowers the adsorption capacities. Besides, the phenolate anions are mostly soluble in the aqueous solution, and stronger adsorbate-water bonds must be broken before adsorption can take place (Terzyk 2003). Similar result was reported for adsorption of reactive red 195 on $\mathrm{TiO}_{2}$ nanoparticles (Belessi et al. 2009). Thus, the rest of the experiments were performed at $\mathrm{pH} 2$.

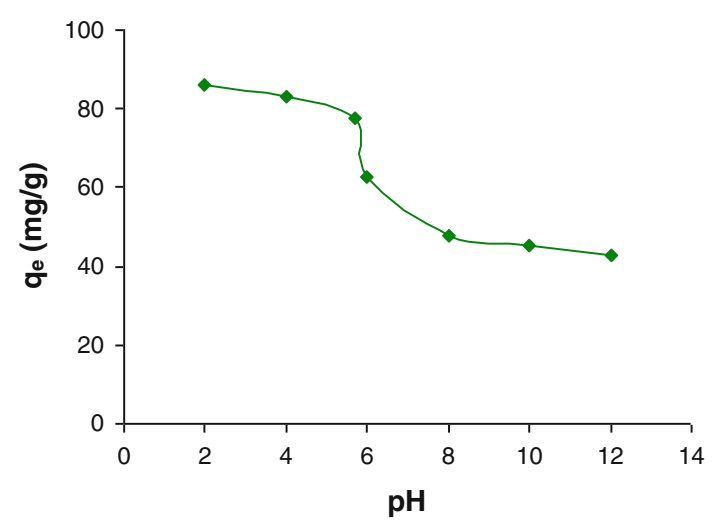

Fig. 3 Effect of $\mathrm{pH}$ on $4 \mathrm{C} 2 \mathrm{NP}$ adsorption onto nano- $\mathrm{TiO}_{2}$ (nano$\mathrm{TiO}_{2}$ dose: $0.01 \mathrm{~g} / 250 \mathrm{~mL}$, initial $4 \mathrm{C} 2 \mathrm{NP}$ conc.: $10 \mathrm{mg} / \mathrm{L}$, temp.: $25^{\circ} \mathrm{C}$, contact time: $1 \mathrm{~h}$ ) 


\section{Effect of initial concentration}

The effect of initial $4 \mathrm{C} 2 \mathrm{NP}$ concentration in the range of $2-10 \mathrm{mg} / \mathrm{L}$ on the adsorption rate of $4 \mathrm{C} 2 \mathrm{NP}$ onto nano$\mathrm{TiO}_{2}$ is shown in Fig. 4. As shown, when the initial 4C2NP concentration is increased from 2 to $10 \mathrm{mg} / \mathrm{L}$ the amount of $4 \mathrm{C} 2 \mathrm{NP}$ adsorbed per unit weight of the nano- $\mathrm{TiO}_{2}$, at equilibrium conditions and the constant temperature as $25^{\circ} \mathrm{C}$, increased from 6 to $86.3 \mathrm{mg} / \mathrm{g}$. This is obvious from the fact that the initial $4 \mathrm{C} 2 \mathrm{NP}$ concentration provides an important driving force to overcome the whole mass transfer resistance. In addition, the increase of the initial concentration of $4 \mathrm{C} 2 \mathrm{NP}$ for the same mass of nano- $\mathrm{TiO}_{2}$ $(0.01 \mathrm{~g} / 250 \mathrm{~mL})$ creates a great increase of molecules of $4 \mathrm{C} 2 \mathrm{NP}$ in the solution. Thus, higher interaction occurred between $4 \mathrm{C} 2 \mathrm{NP}$ and $\mathrm{TiO}_{2}$ nanoparticles (Bekkouche et al. 2004).

\section{Effect of temperature}

To study the effect of temperature, $0.01 \mathrm{~g}$ of nano- $\mathrm{TiO}_{2}$ was added to $250 \mathrm{~mL}$ of $4 \mathrm{C} 2 \mathrm{NP}$ solution with concentration of $10 \mathrm{mg} / \mathrm{L}$ at $\mathrm{pH} 2$ and the experiments were performed at temperatures of $25,35,45$ and $55^{\circ} \mathrm{C}$. Based on results (Fig. 5), the adsorbed amount of $4 \mathrm{C} 2 \mathrm{NP}$ on nano$\mathrm{TiO}_{2}$ increases with the increasing temperature. In fact, the temperature has two important effects, which are known to increase the diffusion rate of the adsorbate molecules across the boundary layer and in the internal pores of the adsorbent particle, owning to the decrease in viscosity of the solution (Onal et al. 2007).

\section{Adsorption isotherm studies}

Adsorption isotherms are important to describe how solutes interact with adsorbent. Adsorption isotherm studies were

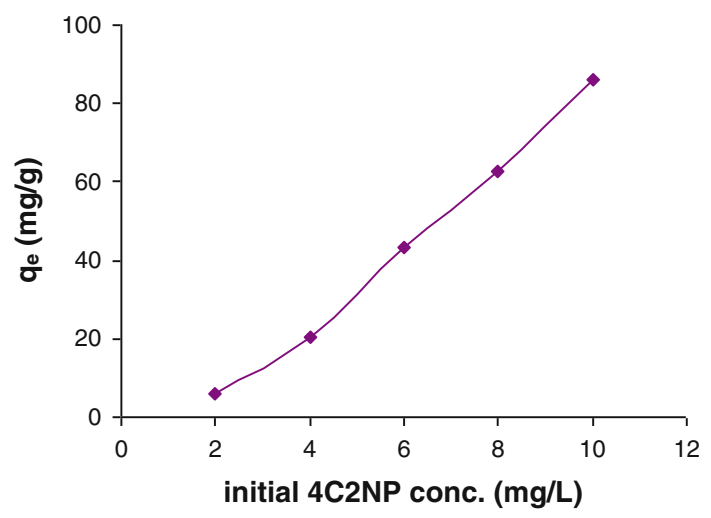

Fig. 4 Effect of $4 \mathrm{C} 2 \mathrm{NP}$ initial conc. on its adsorption onto nano$\mathrm{TiO}_{2}$ (nano- $\mathrm{TiO}_{2}$ dose: $0.01 \mathrm{~g} / 250 \mathrm{~mL}, \mathrm{pH}$ : 2 , temp.: $25^{\circ} \mathrm{C}$, contact time: $1 \mathrm{~h})$

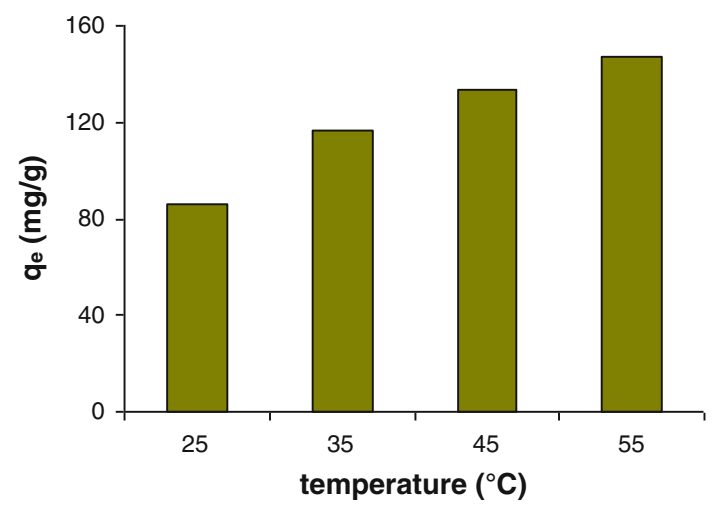

Fig. 5 Effect of temperature on $4 \mathrm{C} 2 \mathrm{NP}$ adsorption onto nano- $\mathrm{TiO}_{2}$ (nano- $\mathrm{TiO}_{2}$ dose: $0.01 \mathrm{~g} / 250 \mathrm{~mL}, \mathrm{pH}: 5.7$, initial $4 \mathrm{C} 2 \mathrm{NP}$ conc.: $10 \mathrm{mg} / \mathrm{L}$, contact time: $1 \mathrm{~h}$ )

carried out with different initial 4C2NP concentrations ranging from 2 to $10 \mathrm{mg} / \mathrm{L}$. Equilibrium adsorption isotherm data were analyzed according to the linear forms of Langmuir, Freundlich and Temkin adsorption isotherm equations (3-5), respectively:

$\frac{1}{q_{\mathrm{e}}}=\left(\frac{1}{K_{\mathrm{L}} q_{\mathrm{m}}}\right) \frac{1}{C_{\mathrm{e}}}+\frac{1}{q_{\mathrm{m}}}$

$\operatorname{Ln} q_{\mathrm{e}}=\left(\frac{1}{n}\right) \operatorname{Ln} C_{\mathrm{e}}+\operatorname{Ln} K_{\mathrm{F}}$

$q_{\mathrm{e}}=B_{1} \operatorname{Ln} C_{\mathrm{e}}+B_{1} \operatorname{Ln} K_{\mathrm{T}}$

where $C_{\mathrm{e}}(\mathrm{mg} / \mathrm{L})$ is the equilibrium concentration of $4 \mathrm{C} 2 \mathrm{NP}, q_{\mathrm{e}}(\mathrm{mg} / \mathrm{g})$ is the amount of $4 \mathrm{C} 2 \mathrm{NP}$ adsorbed at equilibrium, $q_{\mathrm{m}}(\mathrm{mg} / \mathrm{g})$ is the maximum adsorption at monolayer and $K_{\mathrm{L}}(\mathrm{L} / \mathrm{mg})$ is the Langmuir constant including the affinity of binding sites. $K_{\mathrm{F}}\left[(\mathrm{mg} / \mathrm{g})(\mathrm{L} / \mathrm{mg})^{1 / n}\right]$ and $n$ are the Freundlich constants indicating adsorption capacity and intensity, respectively. $K_{\mathrm{T}}(\mathrm{L} / \mathrm{g})$ and $B_{1}$ are the Temkin constants $\left(K_{T}\right.$ is the equilibrium binding constant and $B_{1}$ is related to the heat of adsorption). The values of Langmuir, Freundlich and Temkin parameters were calculated from the slope and intercept of linear plots of $1 / q_{\mathrm{e}}$ versus $1 / C_{\mathrm{e}}, \operatorname{Ln} q_{\mathrm{e}}$ versus $\operatorname{Ln} C_{\mathrm{e}}$ and $q_{\mathrm{e}}$ versus $\operatorname{Ln} C_{\mathrm{e}}$, respectively. Figure $6 \mathrm{a}-\mathrm{c}$ displays the adsorption isotherms plots. The isotherm constants along with the correlation coefficients are listed in Table 1.

It can be seen from the Table 1 that the adsorption process could be explained by all models from comparing the results of the correlation coefficient values. However, careful observation may describe Freundlich isotherm better than others. This means that heterogeneous occupation of the surface may be predominated and also physisorption occurs rather than chemisorption (Nandi et al. 2009). The Freundlich parameters, $K_{\mathrm{F}}$ and $n$ were found to be 2.013 and 0.497 , respectively. A relatively $n \ll 1$ indicates that adsorption intensity is favorable over 

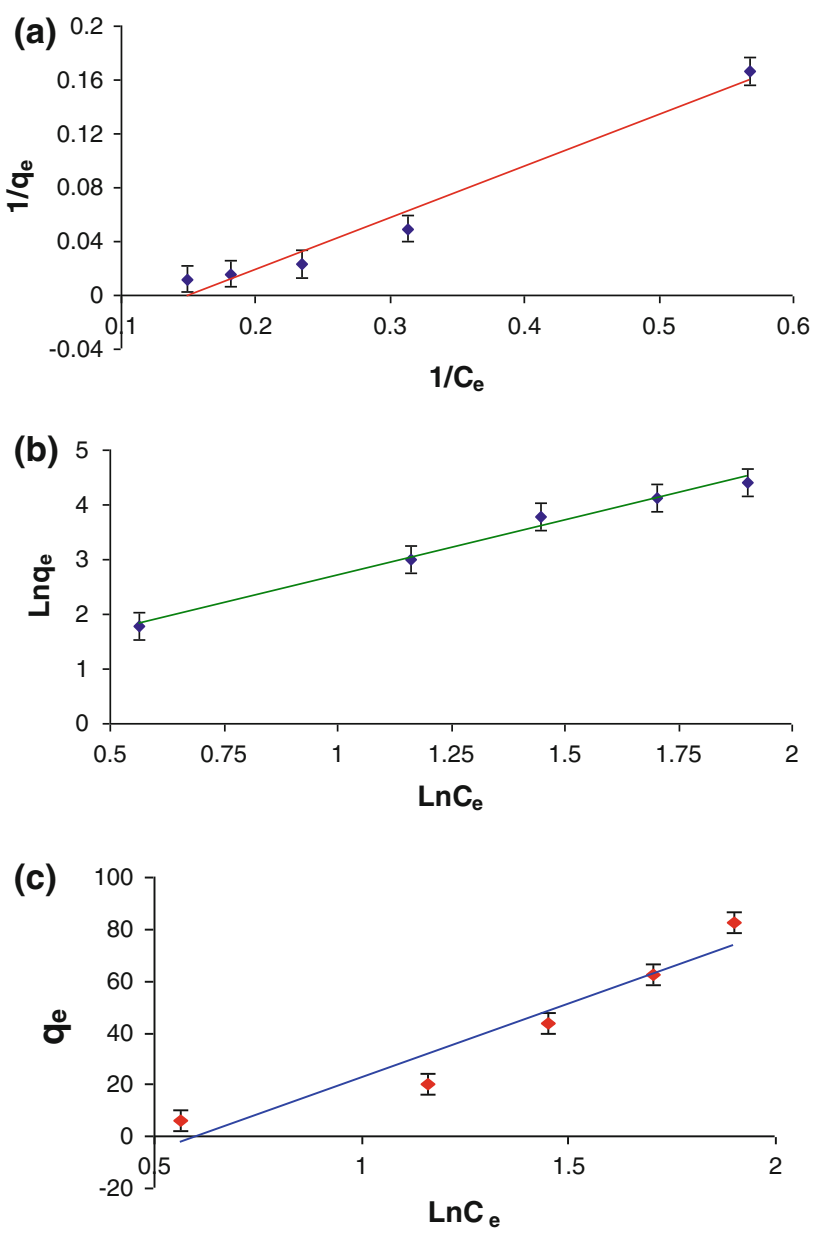

Fig. 6 Plots of linearized Langmuir (a), Freundlich (b) and Temkin (c) adsorption isotherms

Table 1 Isotherm parameters for $4 \mathrm{C} 2 \mathrm{NP}$ adsorption onto nano- $\mathrm{TiO}_{2}$ (nano- $\mathrm{TiO}_{2}$ dose: $0.01 \mathrm{~g} / 250 \mathrm{~mL}, \mathrm{pH}: 2$, temp.: $25^{\circ} \mathrm{C}$, contact time: $1 \mathrm{~h})$

\begin{tabular}{|c|c|c|c|c|c|c|c|c|}
\hline \multicolumn{3}{|c|}{ Langmuir model } & \multicolumn{3}{|c|}{ Freundlich model } & \multicolumn{3}{|c|}{ Temkin model } \\
\hline$q_{\mathrm{m}}$ & $K_{\mathrm{L}}$ & $R^{2}$ & $n$ & $K_{\mathrm{F}}$ & $R^{2}$ & $B_{1}$ & $K_{\mathrm{T}}$ & $R^{2}$ \\
\hline 17.543 & 0.149 & 0.972 & 0.497 & 2.013 & 0.991 & 56.979 & 0.547 & 0.922 \\
\hline
\end{tabular}

the entire range of concentrations studied, while $n>1$ means that adsorption intensity is favorable at high concentrations, but much less at lower concentrations (Hameed et al. 2007). Therefore in the present study, adsorption intensity is favorable over the entire range of concentrations studied.

\section{Conclusion}

This investigation examined the adsorption of 4-chloro-2nitrophenol onto titanium dioxide nanoparticles (Degussa P25) at various conditions. It was found that a trace amounts of nano- $\mathrm{TiO}_{2}(0.01 \mathrm{~g} / 250 \mathrm{~mL})$ shows significant adsorption for $4 \mathrm{C} 2 \mathrm{NP}$. This may be due to the high specific surface area of nanoparticles and the absence of internal diffusion resistance. The results suggested that the adsorption capacity decreased as the $\mathrm{pH}$ rose, but increased with an increase of initial 4C2NP concentration and temperature. The Freundlich isotherm model was found to be the best fitting isotherm model and this means that heterogeneous occupation of the surface may be predominated and also physisorption occurs rather than chemisorption.

Acknowledgments The authors would like to thank from the School of Pharmacy, Tabriz-Iran, specially Dr. Hamidi and Miss Faridi.

\section{References}

Acero JL, Benitez FJ, Leal AI, Real FJ (2005) Removal of phenolic compounds in water by ultrafiltration membrane treatments. J Environ Sci Health A 40(8):1585-1603

Agarry SE, Solomon BO (2008) Kinetics of batch microbial degradation of phenols by indigenous Pseudomonas fluorescence. Int J Environ Sci Tech 5(2):223-232

Anbia M, Ghaffari A (2009) Adsorption of phenolic compounds from aqueous solutions using carbon nanoporous adsorbent coated with polymer. Appl Surf Sci 255(23):9487-9492

Arellano-Cardenas S, Gallardo-Velazquez T, Osorio-Revilla G, Lopez-Cortezl MS, Gomez-Pereal B et al (2005) Adsorption of phenol and dichlorophenols from aqueous solutions by porous clay heterostructure (PCH). J Mex Chem Soc 49(3):287-291

Bekkouche S, Bouhelassa M, Hadj Salah N, Meghlaoui FZ et al (2004) Study of adsorption of phenol on titanium oxide (TiO2). Desalination 166:355-362

Belarbi H, Al-Malack MH (2010) Adsorption and stabilization of phenol by modified local clay. Int J Environ Res 4(4):855-860

Belessi V, Romanos G, Boukos N, Lambropoulou D, Trapalis C (2009) Removal of Reactive Red 195 from aqueous solutions by adsorption on the surface of $\mathrm{TiO} 2$ nanoparticles. J Hazard Mater 170(2):836-844

Benitez FJ, Beltran-Heredia J, Acero JL, Rubio FJ (2000) Rate constants for the reactions of ozone with chlorophenols in aqueous solutions. J Hazard Mater B 79(3):271-285

Bourikas K, Stylidi M, Kondarides DI, Verykios X (2005) Adsorption of acid orange 7 on the surface of titanium dioxide. Langmuir 21(20):9222-9230

Calace N, Nardi E, Petronio BM, Pietroletti M (2002) Adsorption of phenols by peparmill sludge. Environ Poll 118(3):315-319

Chen S, Xu ZP, Zhang O, Lu GQ, Hao ZP, Liu S (2009) Studies on adsorption of phenol and 4-nitrophenol on MgAl-mixed oxide derived from $\mathrm{MgAl}$-layered double hydroxide. Sep Purif Technol 67(2):194-200

Dabhade MA, Saidutta MB, Murthy DVR (2009) Adsorption of phenol on granular activated carbon from nutrient medium:equilibrium and kinetic study. Int J Environ Res 3(4):557-568

Derylo-Marczewska A, Miroslaw K, Marczewski AW, Sternik D (2010) Studies of adsorption equilibria and kinetics of o-, m-, p-nitro- and chlorophenols on microporous carbons from aqueous solutions. Adsorption 16:359-375

Dursun AY, Tepe O (2005) Internal mass transfer effect on biodegradation of phenol by Ca-alginate immobilized Ralstonia eutropha. J Hazard Mater 126:105-111 
Gharbani P, Khosravi M, Tabatabaii SM, Zare K, Dastmalchi S, Mehrizad A (2010) Degradation of trace aqueous 4-chloro-2nitrophenol occurring in pharmaceutical industrial wastewater by ozone. Int J Environ Sci Tech 7(2):377-384

Gonzalez-Serrano E, Cordero T, Rodriguez-Mirasol J, Cotoruelo L, Rodriguez JJ (2004) Removal of water pollutants with activated carbons prepared from H3PO4 activation of lignin from kraft black liquors. Water Res 38(13):3043-3050

Hameed BH, Ahmad AL, Latif KNA (2007) Adsorption of basic dye (methylene blue) onto activated carbon prepared from rattan sawdust. Dyes Pigments 75(1):143-149

Haque E, Khan NA, Talapaneni SN, Vinu A, Jegal J, Jhung SH et al (2010) Adsorption of phenol on mesoporous carbon cmk-3: effect of textural properties. B Kor Chem Soc 31(6):1638-1642

Hashizume H (2004) Adsorption of some aromatic compounds by a synthetic mesoporous silicate. J Environ Sci Health A 39(10):2615-2625

Khan Z, Anjaneyulu Y (2005) Influence of soil components on adsorption-desorption of hazardous organics-development of low cost technology for reclamation of hazardous waste dumpsites. J Hazard Mater B 118:161-169

Kumar A, Kumar S, Kumar S, Gupta D (2007) Adsorption of phenol and 4-nitrophenol on granular activated carbon in basal salt medium: equilibrium and kinetics. J Hazard Mater 147:155-166

Lei Z, Yuan Z, Hongmei L, Na L, Xueyan L, Xuejun G (2010) Kinetic and thermodynamic studies of adsorption of gallium(III) on nano-TiO2. Rare Metals 29(1):16-20

Mahvi AH (2008) Application of agricultural fibers in pollution removal from aqueous solution. Int J Environ Sci Tech 5(2):275-285

Nandi BK, Goswami A, Purkait MK (2009) Adsorption characteristics of brilliant green dye on kaolin. J Hazard Mater 161(1):387-395

Onal Y, Akmil-Basar C, Sarici-Ozdemir C (2007) Investigation kinetics mechanisms of adsorption malachite green onto activated carbon. J Hazard Mater 146(1):194-203
Robert D, Parra S, Pulgarin C, Krzton A, Weber JV (2000) Chemisorption of phenols and acids on TiO2 surface. Appl Surf Sci 167:51-58

Roostaei N, Tezel FH (2004) Removal of phenol from aqueous solutions by adsorption. J Environ Manage 70(2):157-164

Samarghandi MR, Nouri J, Mesdaghinia AR, Mahvi AH, Nasseri S, Vaezi F (2007) Efficiency removal of phenol, lead and cadmium by means of UV/TiO2/H2O2 processes. Int J Environ Sci Tech 4(1):19-25

Saritha P, Aparana C, Himabindu V, Anjaneyulu Y (2007) Advanced oxidation of 4-chloro-2-nitrophenol (4C-2-NP): a comparative study. J Hazard Mater 149(3):609-614

Sokol W, Korpal W (2004) Determination of the optimal operational parameters for a three-phase fluidized bed bioreactor with a light biomass support when used in treatment of phenolic wastewaters. Biochem Eng J 20:49-56

Subramanyam B, Das A (2009) Linearized and non-linearized isotherm models comparative study on adsorption of aqueous phenol solution in soil. Int J Environ Sci Tech 6(4):633-640

Terzyk AP (2003) Further insights into the role of carbon surface functionalities in the mechanism of phenol adsorption. J Colloid Interf Sci 268:301-329

Tseng RL, Wu KT, Wu FC, Juang RS (2010) Kinetic studies on the adsorption of phenol, 4-chlorophenol, and 2,4-dichlorophenol from water using activated carbons. J Environ Manage 91:2208-2214

Wang Z, Zhang LS, Jing ZQ (2010) Study the adsorption of phenol on attapulgite-zeolite nano-structure adsorbent from aqueous solution. Key Eng Mat 426:118-121

WHO (1963) Guidelines for drinking-water quality: international standards for drinking water. World Health Organization, Geneva 